\title{
Urgences
}

\section{Imaginer la part des choses}

\section{Esther Loiselle}

Numéro 27, mars 1990

Images imaginaires

URI : https://id.erudit.org/iderudit/025565ar

DOI : https://doi.org/10.7202/025565ar

Aller au sommaire du numéro

Éditeur(s)

Urgences

ISSN

0226-9554 (imprimé)

1927-3924 (numérique)

Découvrir la revue

Citer ce document

Loiselle, E. (1990). Imaginer la part des choses. Urgences, (27), 10-13.

https://doi.org/10.7202/025565ar d'utilisation que vous pouvez consulter en ligne.

https://apropos.erudit.org/fr/usagers/politique-dutilisation/ 


\title{
Imaginer la part des choses Esther Loiselle ${ }^{1}$
}

\begin{abstract}
Autant dire que les livres n'existent que dans l'histoire où ils entrent par la lecture et que le a je » de l'écrivain refuse aussi bien de se confier à son mystère personnel que de s'évader du monde. Si l'œuvre est trouée, si elle ouvre par là à la lecture, c'est qu'elle inaugure du même coup une histoire dont elle est, à chaque coup, non pas la réduction, non pas l'expression, mais l'avènement.
\end{abstract}

Fernand Dumont 2

Que de fois ai-je succombé aux charmes de l'esprit: fin, vif, subtil, inventif, audacieux. Les constructions intellectuelles édifiantes m'ont plus d'une fois prise sur le fait: bouche bée et comme captive d'une fascination qu'elles opèrent presque invariablement, mon index lissant les pages et cherchant à prendre appui sur la magie des mots. Alors se dessine le sourire à force d'opiner, et au coin de l'œil, une pointe d'envie. Fascinée, certes je le suis. Mais [...]

Moi, je me recueille dans les choses... comme d'autres dans les prières. Je suis pour ainsi dire éprise des choses-detous-les-jours; elles font naître en moi une forme de jouissance que d'aucuns allieraient à la spiritualité. Elles m'atteignent d'autant mieux qu'en elles je me reconnais, m'émeuvent d'autant plus qu'elles sont fugaces. Les sensations produites par un contact étroit avec le "donné" - Michel Serres souligne que l'on désigne ainsi ce qui vient du monde au corps sont mult ipliées par autant de fois qu'un auteur s'attache à la description de gens, de lieux ou d'événements qui autrement me seraient étrangers. C'est à cela que me convie le

1 Extraits d'un mémoire de maîtrise en éducation. Esther Loiselle, L'écriture au quotidien: la pédagogie, Rimouski, Université du Québec à Rimouski, 1987.

2 Fernand Dumont, Le lieu de l'homme, Montreal, HMH, 1968, p. 80. 
roman: une connaissance venant du corps, «[...] élargie et complète, assise et fondée sur la douceur et la compétence des sens [...]" 3 . Mais si la multiplicité des choses qui s'offrent à la conscience l'étoffe indubitablement, cette connaissance n'a nul besoin, pour se manifester, de sources élargies de façon compulsive. Il suffit d'un livre, toujours le même peut-être, et la voilà qui se renouvelle à l'invite de qui lui fait une place. Je reprends le roman dont hier j'ai fait mon pain et pour l'avoir bien pétri j'y crois retrouver intactes les traces que sur moi il avait laissées. Or il se dérobe, me conduit en ce lieu qu'aujourd'hui j'occupe et qui me convie à de nouvelles perceptions. Mille fois je le lis, il se recompose mille fois. J'entretiens avec lui une intimité qui fonde nos rapports: il n'a de cesse de me révéler à ce que je suis, et en retour, je le confirme pour toujours, et moi, avec lui. [...]

Ce que je vois dans le roman? D'abord des mots, peut-être ceux-là même que je n'ai pas su trouver alors que moi, prise au ras de mon existence, happée tout entière par l'occupation d'entretenir de façon continue mes rapports aux choses, je plongeais ma parole dans un état de torpeur. Du reste, en ces instants, elle s'accommodait de n'être pas forcément présente. Mais le roman la relance, et par un biais qui est sous-tendu dans ma relation avec les choses. Car cette relation, pourtant marquée au sceau d'une étroite complicité, n'arrive pas à dissiper un certain trouble qui s'insinue parfois alors que ma conscience se dérobe et s'avise de suspendre momentanément le cours tranquille de ma présence au monde. Est-ce la curiosité qui alors me pousse vers le roman afin de retrouver dans ses pages l'amorce de perceptions nouvelles trop rapidement introduites par une échappée furtive de ma conscience? Qu'ai-je entrevu dans la touée qui me fasse vouloir prolonger cet instant si ce n'est la possibilité subitement pressentie qu'il pourrait bien exister une nouvelle façon d'appréhender le monde. Et voilà que ma parole trépigne et s'agite, alors qu'elle se reconnaît dans le miroir ainsi tendu. Car le roman posé entre moi et mon quotidien m'offre le spectacle de mon propre reflet: je m'y découvre mais comme détachée de ce à quoi m'avaient habituée les perceptions issues de mon voisinage intense avec les choses. [...]

Qu'on ne s'y méprenne pas: le roman ne raconte pas ma vie telle qu'il m'est donné de la vivre, les moments de passion 
succédant aux actes routiniers, les uns et les autres ayant convenu de s'unir dans un espace-temps aux proportions fluctuantes. Non. Ce que me raconte le roman, c'est justement la brisure de cette entrave temporelle, brisure par laquelle s'échappe le sens, celui d'un monde parallèle à l'intérieur duquel il m'est donné d'embrasser tout d'un bloc le destin [...].

Je suis ce que me renvoient mes perceptions: je me meus dans un univers défini par les rapports que j'entretiens - ou crois entretenir - avec le monde qui m'entoure et qui à force de fréquentation me devient signifiant. Et mon corps et mon esprit s'abreuvent à l'assurance tranquille de ces significations premières et peu s'en faut qu'ils s'y complaisent, absolument. Le roman intervient en liquidant mes repères : là où je crois reconnaître mes conduites, il me déplace ailleurs, le moment de le lire. Et puis je reviens à ce que je crois mes habitudes, mais qui sont modifiées, tout comme mes perceptions auxquelles elles devaient leur existence. Cet «[...] ébranlement des structures congelées de la perception [...]» 4 agit comme garant du renouvellement de mes conduites: certes, je reviens au monde coutumier, mais il ne sera plus tout à fait le même, et moi avec lui. [...]

De toutes les formes d'art qui me sont offertes, la littérature est celle [...] en laquelle mon imaginaire, constamment sollicité par la concrétude des choses, se plaisant en leur compagnie, trouve naturellement un appui. C'est un peu comme si les choses grandissaient en importance et révélaient leur véritable force à travers l'énergie consentie par les mots servant à les désigner. Qui n'a pas entendu les hommes du Grand Nord parler de la neige ne la connait pas. De la même façon, le roman me réintroduit auprès d'un donné dont j'avais cru cerner les subtilités à force de fréquentation, mais qui m'est restitué, au terme de mes lectures, sous de nouveaux couverts, ceux-là insoupçonnés. Et je me retrouve subitement entourée de choses neuves parce que je puis désormais varier leurs qualités au rythme des épithètes fraîchement acquises, et leur contour s'émancipe de l'enveloppe trop étroite dans laquelle mon ignorance des mots les avai t jusque-là confinées, et les voilà qui s'épanouissent à l'infini, ne me laissant d'autre choix que celui d'adapter mon pas au leur. 
Le roman agit, et comme médiateur. S'il appartient aux sens de me livrer la clé de voûte du donné, s'il leur revient d'avoir su si bien m'associer aux choses, ils accusent en revanche une impuissance à rendre compte du sens: celui qu'au donné je prête. Car si le donné devient pour moi l'objet d'une émotion, c'est qu'il est médiatisé par le roman. Dès lors que je le lis, m'est offert largement déployé le répertoire de sens en l'absence duquel les sensations resteraient fermées sur elles-mêmes. [...] 